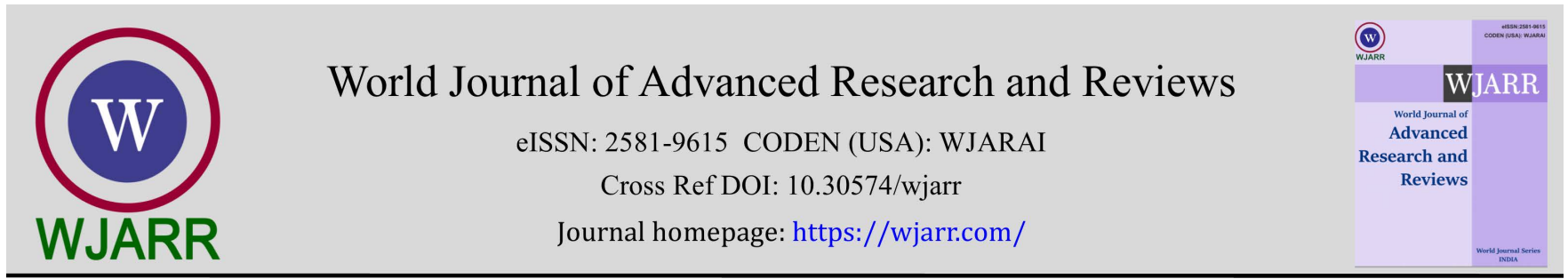

(RESEARCH ARTICLE)

\title{
Impact of malaria prophylaxis on Plasmodium Parasitemia among pregnant women receiving care at Federal Medical Centre, Owerri
}

\author{
CC Duru 1, SD Lawson 2, *, SO Enyinnaya ${ }^{2}$ and L Sapira-Ordu ${ }^{3}$ \\ ${ }^{1}$ Department of medical microbiology and parasitology University of Port Harcourt Teaching Hospital. \\ 2 Department of medical microbiology and parasitology, Rivers State University Teaching Hospital. \\ ${ }^{3}$ Department of Obstetrics \& Gynecology, Rivers State University Teaching Hospital.
}

World Journal of Advanced Research and Reviews, 2022, 13(01), 655-659

Publication history: Received on 17 December 2021; revised on 22 January 2022; accepted on 24 January 2022

Article DOI: https://doi.org/10.30574/wjarr.2022.13.1.0073

\begin{abstract}
Background: Malaria during pregnancy harms the baby's health. As personal protection and chemoprevention therapy, insecticide-treated nets (ITN) and intermittent preventive treatment (IPTps) of malaria during pregnancy are recommended. According to the World Health Organization, the introduction of IPTp and ITN constituted a defining moment in malaria prevention in endemic areas during pregnancy. The purpose of this research was to see if there was an association between the usage of IPTp and ITNs and maternal malaria prophylaxis.
\end{abstract}

Methods: A cross-sectional study was conducted on 327 pregnant women who presented at the federal medical center in Owerri. Participants' blood samples were taken for microscopic inspection to detect malaria parasites using established procedures. Pregnant women provided information on their use of IPTp and ITN. Descriptive statistics were used to characterize the independent variables, and chi-square was used for categorical variables as needed using Microsoft Excel 2016.

Results: There was a significant association between IPTp use in the prevention of malaria in pregnancy $(\mathrm{P}-\mathrm{Value}=$ $<0.001$ ) and ITN use in the prevention of malaria in pregnancy respectively (P-Value $=<0.001$ ).

Conclusions: Maternal Malaria is a major public health issue that poses severe danger to pregnant women and their fetuses. IPTp and ITN use are beneficial in malaria prevention among this population.

Keywords: ITN; IPTp; Malaria; Maternal; Owerri

\section{Introduction}

Malaria during pregnancy is a major public health issue that poses severe dangers to the pregnant mother, her fetus, and the newborn child [1]. Each year, an estimated 125 million pregnant women worldwide are at risk of malaria infection, with 30 million from Sub-Saharan Africa [2]. Furthermore, it is predicted that 75,000-200,000 children and 10,000 women die each year as a result of malaria in pregnancy [2,3]. In Nigeria, as in many other endemic regions in Africa, pregnant women and children under the age of five face the brunt of the malaria burden. Malaria is thought to cause 3-5\% maternal anemia, 8-14 \% low birth weight (LBW), and 3-8\% infant mortality during pregnancy. [4]. Particularly, Plasmodium falciparum infections in pregnancy contribute to approximately $11 \%(100,000)$ of neonatal deaths due to low birth weight in areas of Africa where malaria is endemic $[3,5,6]$.

\footnotetext{
${ }^{*}$ Corresponding author: SD Lawson

Department of medical microbiology and parasitology, Rivers State University Teaching Hospital.

Copyright $(2022$ Author(s) retain the copyright of this article. This article is published under the terms of the Creative Commons Attribution Liscense 4.0.
} 
World Health Organisation promotes malaria prevention techniques during pregnancy in malaria-free areas in Africa, where roughly 25 million pregnancies are infected each year [7]. These interventions are based on the use of insecticidetreated nets (ITNs) and the administration of intermittent preventative treatment (IPTp) [7].

IPTp entails giving a woman a single curative dose of an effective anti-malarial drug at least twice during her pregnancy, regardless of whether she is infected or not. During antenatal visits, the medication is given under supervision. Because of its safety and efficacy in pregnancy, the WHO currently recommends sulphadoxine-pyrimethamine and personal protection methods that prevent man from coming into touch with mosquitoes are known as ITNs [7, 8]. In hightransmission areas, the introduction of IPTp and ITN marked a watershed moment in malaria prevention during pregnancy [7]. The goal of this study was to look at the links between IPTp and ITN use and malaria prevention in pregnant women receivingantenatal care at Federal Medical Centre, Owerri.

\section{Material and methods}

\subsection{Study Design}

The cross-sectional study was conducted in the obstetrics units at Federal Medical Center (FMC).

\subsection{Study Population}

Pregnant women who attend the antenatal clinic of the Federal Medical Center (FMC) in Owerri make up the research population.

\subsection{Sampling and Sample Size for the study}

The sample size for proportions formula was used to calculate a sample size of 327 using a 29\% prevalence of maternal malaria(9) as shown below: $n=z 2 p q / d 2$ where $n=$ minimum sample size, $z=$ confidence interval of 95 percent which is equivalent to the coefficient of $1.96, \mathrm{p}=$ proportion/prevalence of the previous study, $\mathrm{q}=$ alternate proportion (1-p), $\mathrm{d}=$ level of precision set at $5 \%$ To choose the participants, a stratified sampling procedure was used.

Blood samples were taken from the subjects for microscopic analysis to detect malaria parasites, as described bySatio et al [10]. Within one hour following childbirth, placental blood was taken by incising the placenta's cleansed maternal surface (basal plate). [10]. The samples' thin and thick blood films were transferred to grease-free glass slides and stained for malaria parasite identification using established procedures [11].

\subsection{Data Collection}

The study participants were asked to fill out a structured PROFORMA data collecting sheet with demographic information, ITN use, IPTp use, and malaria diagnoses.

\subsection{Data analyses}

Statistical Package for Social Sciences (SPSS) version 25 was employed for the statistical analysis. Descriptive statistics (means, standard deviation, frequency, and percentage) were used to summarize the patients' characteristics. Chisquare was used to assess the association between IPTp and ITN use and the occurrence of maternal malaria. A p-value less than 0.05 was considered significant.

\subsection{Ethical Consideration}

Ethical approval to carry out the study was obtained from the Research and Ethics Committees of the Federal Medical Center Owerri before the commencement of the study. A written willing informed consent was obtained from each participant before they were included in the study.

\section{Results and discussion}

A total of 327 patients were included in the study. Tables 1 shows the distribution of the socio-demographic characteristics of the participants including age, education, and occupation. The mean age of study participants was $30.68 \pm 5.71$ years. Some of the study patients181 (55.35\%) were between $30-39$ years oldand was closely followed by those between 18 - 29years130 (39.76\%). Some 151 (46.18\%) respondents were self-employed. Some 173 (52.91\%) of the patients had achieved tertiary education. Table 2 shows there was no significant association between gravidity and malaria in pregnancy. There was a significant association between intermittent preventive therapy in the 
prevention of malaria in pregnancy $(\mathrm{P}$-Value $=<0.001)$ and there was a significant association between the use of insecticide-treated net and malaria in pregnancy (P-Value $=<0.001$ ) as shown in tables 3 and 4.

Table 1 Demographic Distribution of Patients

\begin{tabular}{|l|l|l|}
\hline Variable & Frequency (n = 327) & Percent (\%) \\
\hline Age Groups & 130 & 39.76 \\
\hline $18-29$ years & 181 & 55.35 \\
\hline $30-39$ years & 16 & 4.89 \\
\hline $40-49$ years & \multicolumn{2}{|l}{} \\
\hline Occupation & 151 & 46.18 \\
\hline Self Employed & 114 & 34.86 \\
\hline Civil Servants & 1 & 0.31 \\
\hline Housewife & 61 & 18.65 \\
\hline Unemployed & 63 & 19.27 \\
\hline Educational Level & \multicolumn{2}{|l}{} \\
\hline Primary & 80 & 24.46 \\
\hline Secondary & 173 & 52.91 \\
\hline Tertiary & 11 & 3.36 \\
\hline No Formal Education & &
\end{tabular}

Table 2 Relationship between Gravidity and Malaria in Pregnancy

\begin{tabular}{|l|l|l|c|l|}
\hline Gravidity & Positive & Negative & Chi-Square & P-value \\
\hline Gravida 1 & $26(21.14)$ & $43(21.29)$ & 0.01 & $(0.9745)^{* *}$ \\
\hline Gravida 2 & $63(51.22)$ & $99(49.01)$ & 0.14 & $(0.6992)^{* *}$ \\
\hline Gravida 3 & $29(23.58)$ & $48(23.76)$ & 0.01 & $(0.9693)^{* *}$ \\
\hline Gravida 4 & $5(4.07)$ & $10(4.95)$ & 0.13 & $(0.7121)^{* *}$ \\
\hline Gravida 5 & $0(0.00)$ & $2(0.99)$ & 1.22 & $(0.5280)^{* *}$ \\
\hline
\end{tabular}

Table 3 Malaria in Pregnancy and Use of IPT

\begin{tabular}{|l|c|c|c|}
\hline \multirow{2}{*}{ Malaria in Pregnancy } & \multicolumn{2}{|l|}{ IPT USE } & \multirow{2}{*}{ Chi-Square P-value } \\
\cline { 2 - 3 } & Yes & No & \\
\hline Positive & $80(29.09)$ & $45(86.54)$ & \multirow{2}{*}{$61.110 .0001^{*}$} \\
\hline Negative & $195(70.91)$ & $7(13.46)$ & \\
\hline
\end{tabular}

\section{Discussion}

Malaria morbidity and death have been demonstrated to be reduced when ITNs are used alone [12]. The Roll Back Malaria (RBM) alliance, on the other hand, advocates using intermittent preventative treatment (IPT) also in areas where malaria transmission is steady to reduce the disease's burden among pregnant women $[13,14]$. In many malaria- 
endemic regions of Sub-Saharan Africa, the execution of the IPTp policy has been plagued by periodic shortages of the program medicine, denying pregnant women on prenatal consultations access to the treatment $[15,16]$. This may be attributed to some women who tend to be consistent with their visits to the antenatal clinic. Our research found a link between IPTp, ITN use, and malaria prophylaxis in pregnancy among pregnant women attending the Federal Medical Center (FMC) at Owerri's antenatal clinic. It was discovered that pregnant women who used IPTp and ITN had a reduced rate of maternal malaria than those who did not. Our findings are consistent with those of an earlier study that found a link between IPTp and ITN use and maternal mortality, However, the study also found that ITN alone did not provide complete protection [17]. Nonetheless, our analysis had a flaw: it did not reveal the direction or magnitude of the relationship between various preventive interventions and maternal mortality. Consequently, more robust study designs are recommended in further studies in Nigeria.

\section{Conclusion}

Maternal Malaria is a major public health issue that poses severe danger to pregnant women and theirfetuses.IPTp and ITN use are beneficial in malaria prevention among this population.

\section{Compliance with ethical standards}

\section{Acknowledgments}

Mother, Baby and Adolescent Care Global Foundation.

\section{Disclosure of conflict of interest}

There was no conflict of interest.

\section{Statement of informed consent}

Informed consent was obtained from all individual participants included in the study.

\section{Funding}

There was no funding.

\section{References}

[1] Ukibe SN, Ukibe NR, Mbanugo JI, Ikeakor LC. Prevalence of malaria among pregnant women attending antenatal clinics in hospitals in Anambra State, south-east, Nigeria. Nigerian journal of Parasitology. 2016; 37(2).

[2] Azizi SC. Uptake of Intermittent Preventive Treatment for Malaria during Pregnancy with SulphadoxinePyrimethamine (IPTp-SP) in Malawi after adoption of updated World Health Organization policy: An Analysis of Demographic and Health Survey. 2015-2016.

[3] Roll Back Malaria Partnership. The contribution of malaria control to maternal and newborn health. In: Progress \& impact. Geneva: World Health Organization. 2014.

[4] Chua CL, Hasang W, Rogerson SJ, Teo A. Poor birth outcomes in malaria in pregnancy: Recent insights into mechanisms and prevention approaches. Frontiers in immunology. 2021; 12.

[5] Eisele TP, Larsen DA, Anglewicz PA, Keating J, Yukich J, Bennett A, Hutchinson P, Steketee RW. Malaria prevention in pregnancy, birthweight, and neonatal mortality: a meta-analysis of 32 national cross-sectional datasets in Africa. Lancet Infect Dis. 2012; 12(12): 942-949.

[6] Dombrowski JG, Souza RM, Silva NR, Barateiro A, Epiphanio S, Gonçalves LA, Marinho CR. Malaria during pregnancy and newborn outcome in an unstable transmission area in Brazil: A population-based record linkage study. PloS one. 21 Jun 2018; 13(6): e0199415.

[7] Bakken L, Iversen PO. The impact of malaria during pregnancy on low birth weight in East-Africa: a topical review. Malaria Journal. 2021; 20(1): 1-9.

[8] Mikomangwa WP, Minzi O, Mutagonda R, Baraka V, Mlugu EM, Aklillu E, Kamuhabwa AA. Effect of sulfadoxinepyrimethamine doses for prevention of malaria during pregnancy in hypoendemic area in Tanzania. Malaria journal. 2020; 19(1): 1-1. 
[9] Agomo CO, Oyibo WA, Anorlu RI, Agomo PU. Prevalence of Malaria in Pregnant Women in Lagos, South-West Nigeria. Korean J Parasitol [Internet]. 2009 [cited 2021 Jul 15].; 47(2): 179.

[10] Saito M, Gilder ME, Nosten F, Guérin PJ, McGready R. Methodology of assessment and reporting of safety in antimalarial treatment efficacy studies of uncomplicated falciparum malaria in pregnancy: a systematic literature review. Malar J 2017161 [Internet]. 2017 Dec 18 [cited 2021 Jul 15].; 16(1): 1-10.

[11] Comar SR, Malvezzi M, Pasquini R. Evaluation of criteria of manual blood smear review following automated complete blood counts in a large university hospital. Rev Bras HematolHemoter [Internet]. 2017 [cited 2021 Jul 15].; 39(4): 306-17.

[12] Lindsay SW, Thomas MB, Kleinschmidt I. Threats to the effectiveness of insecticide-treated bednets for malaria control: thinking beyond insecticide resistance. The Lancet Global Health. 2021; 9(9): e1325-31.

[13] Sonibare 00, Bello IS, Olowookere SA, Shabi O, Makinde NO. Effect of malaria preventive education on the use of long-lasting insecticidal nets among pregnant females in a Teaching Hospital in Osun state, south-west Nigeria. Parasite epidemiology and control. 1 Nov 2020; 11: e00182.

[14] Ameh S, Owoaje E, Oyo-Ita A, Kabiru CW, Akpet OE, Etokidem A, Enembe O, Ekpenyong N. Barriers to and determinants of the use of intermittent preventive treatment of malaria in pregnancy in Cross River State, Nigeria: a cross-sectional study. BMC pregnancy and childbirth. 2016; 16(1): 1-9.

[15] FJ Mpogoro, D Matovelo, A Dosani, S Ngallaba, M Mugono, HD Mazigo. Uptake of intermittent preventive treatment with sulphadoxine-pyrimethamine for malaria during pregnancy and pregnancy outcomes: a crosssectional study in Geita district, North-Western Tanzania," Malaria Journal. 2014; 13: 455.

[16] VN Orish, OS Onyeabor, JN Boampong, et al. Prevalence of intermittent preventive treatment with sulphadoxinepyrimethamine (IPTp-Sp) use during pregnancy and other associated factors in Sekondi-Takoradi, Ghana," African Health Sciences. 2015; 15(4): 1087-1096.

[17] Agyeman YN, Newton SK, Annor RB, Owusu-Dabo E. The Effectiveness of the Revised Intermittent PreventiveTreatment with SulphadoxinePyrimethamine (IPTp-SP) in thePrevention of Malaria among Pregnant Women inNorthern Ghana.2020 Journal of Tropical Medicine. 2020, Article ID 2325304: 9. 